\title{
COCHES, CARROZAS Y SILLAS DE MANO EN LA MONARQUÍA DE LOS AUSTRIAS ENTRE 1600 Y 1700: EVOLUCIÓN DE LA LEGISLACIÓN
}

\author{
ALEJANDRO LÓPEZ ÁLVAREZ* \\ Instituto Universitario de la UAM: «La Corte en Europa»
}

RESUMEN: La introducción de los coches en las caballerizas de las cortes europeas fue un proceso que se desarrolló durante el siglo XVI. En Castilla este uso se afianzó a raíz del asentamiento definitivo de la corte en Madrid (1561). Desde entonces, el coche contribuyó no poco a cambiar la planta de la caballeriza y sus etiquetas, así como las apariciones del rey. Al mismo tiempo, fue asimilado paulatinamente a la nobleza, el sector social que estaba empezando a gobernar en lugar de los letrados, como manifestaron las pragmáticas de 1578 y 1593. Pero la unión del coche y el cortesano fue definitiva desde 1611, mediante la institucionalización de su uso. A partir de entonces, para ir en carruaje era necesario alcanzar una licencia del Consejo de Castilla, lo que de hecho convirtió a este uso en estricto monopolio de las elites que gobernaban la Monarquía, es decir, la aristocracia cortesana, los ministros y criados de la Casa real, los altos eclesiásticos y quienes tuvieran estrechas relaciones con ellos en los grandes centros urbanos. Culminada la institucionalizacion, se procedió por un lado, a tratar de fiscalizar los coches (en 1651, 1658, 1667, 1675, 1684 o 1688) y por otro, se dieron una serie de medidas dirigidas a que el coche siguiera siendo monopolio de una pequeña élite cortesana, las más importantes de las cuales fueron las pragmáticas de 1674, 1678, 1684 y 1691.

Palabras Clave: Corte. Cortesanos. Legislación suntuaria. Coches. Sillas de mano.

ABSTRACT: The introduction of carriages at the European Courts was a process which took place during the 16th Century. In Castille its use established in the course of the definitive settling down of the Court in Madrid (1561). From this time on,

* Este trabajo se inserta dentro del proyecto dirigido por el profesor J. Martínez Millán, «El tiempo del Quijote: Corte, cultura y gobierno en la Monarquía de Felipe III», financiado por el Ministerio de Ciencia y Tecnología (número de referencia BHA2002-02969). 
coaches contributed considerably to change staff and etiquette of the Royal Stables, as well as the public appearences of the King. At the same time, from the end of the 1570's, the coach was adopted by the aristocracy, the social class which was beginning to rule in stead of the "Letrados», as the «pragmaticas» (laws against luxury) of 1578 an 1593 reveal. The alliance between carriage and courtier however became definitive from 1611 on, when the use of carriages was institionalized. From that moment on it was necessary to obtain a licence from the "Consejo de Castilla» in order to go by carriage, wich in deed converted its use in an exclusive domain of the elites governing the monarchy, that is, of the court aristocracy, the ministers and servants of the royal house, the high clergy and those habitants of great urban centres with good relations to the latter. Once the institutionalisation was concluded around 1630, on the one hand efforts were made to fiscalize carriages (in 1651, 1658, 1667, 1675, 1684 and 1688) and of the other, several measures aiming to maintaing the monopoly of a small cout elite were carried through, the most important of wich were the pragmáticas of 1674, 1678, 1684 and 1691.

KEY WORDS: Court. Courtier. Law against luxury. Coaches. Sedan chairs.

Tradicionalmente, los intentos de explicar la génesis y la evolución del «Estado Moderno» proyectaron en el pasado las estructuras del Estado burgués del siglo XIX. Cualquier manifestación política o institucional propia de las monarquías europeas de época Moderna era adscrita en sus moldes institucionales, mientras se ignoraban o se malinterpretaban aquellos organismos y prácticas que no tenían fácil acomodo en esa estructura política. Entre las instituciones ignoradas se encontraban la corte y la Casa real, a las que como mucho se estudiaba desde un punto de vista cultural o ceremonial, siempre de importancia secundaria en el orden político. En las últimas décadas, sin embargo, el estudio de la corte y de la Casa real se viene mostrando como la forma más adecuada de conocer las formas de poder del Antiguo Régimen¹. Fenómenos que ni siquiera alcanzaban la categoría de objeto de análisis y quedaban relegados al anecdotario, se convierten, a la luz de los estudios sobre la corte, en instrumentos esenciales para entender la forma de hacer política en las Monarquías modernas. Un caso paradigmático es el uso del coche, analizado sobre todo desde un punto de vista técnico o artístico como se ha hecho preferentemente en los

Abreviaturas: AHN: Archivo Histórico Nacional - AGS: Archivo General de Simancas - AMG: Archivo Municipal de Granada - AMS: Archivo Municipal de Sevilla - AMV: Archivo Municipal de Vitoria - BNM: Biblioteca Nacional (Madrid) - BPM: Biblioteca Pública de Mallorca - BPR: Biblioteca de Palacio Real (Madrid) - CC: Cámara de Castilla - REH: Real Academis de la Historia (Madrid) - RABM: Revista de Archivos, Bibliotecas y Museos. - RGS : Registro General del Sello

1 Para los estudios sobre la corte en España me remito a los principales trabajos del equipo de investigación dirigido por el profesor MARTínez MilLÁn, J.: Felipe II (1527-1598) Europa y la Monarquía Católica, Madrid, 1998, 5 vols; Felipe II (1527-1598) La configuración de la Monarquía hispana, Valladolid, 1998; La Corte de Carlos V, Madrid, 2000, 5 vols. y La Monarquía de Felipe II. La Casa del Rey, Madrid, 2005, 2 vols. 
países de lengua alemana ${ }^{2}$, mientras en España ha sido considerado a lo sumo como muestra de la decadencia moral y de los estragos sociales que ocasionaba el lujo en la corte barroca ${ }^{3}$.

\section{EL USO DE LOS COCHES Y LA EVOLUCION POLÍTICA DE LA MONARQUÍA}

La introducción de los coches en las cortes europeas fue un proceso paulatino que se desarrolló especialmente a lo largo del siglo XVI. Durante la Edad Media y sobre todo el Renacimiento, no se había olvidado que el carro había sido en las culturas antiguas atributo propio de los dioses y los reyes y en el mundo grecorromano de los dioses, los héroes y algunas dignidades, de forma que cuando el uso de los coches se fue extendiendo desde 1500 en adelante, fue consecuente vincularlos con el poder político y dotarlos de un aura de sacralidad. Los nuevos coches, junto a otros inventos anteriores como las literas y los trineos y otros posteriores, como las sillas de mano y las carrozas, conformaron lo que denominamos vehículos representativos. Todos ellos, encuadrados inicialmente en las caballerizas reales (la sección de la Casa real encargada de la imagen publica del monarca) y más tarde en las de los ministros y caballeros, introdujeron

2 El primer trabajo destacado fue el de KreISEL, H.: Prunkwagen und Schlitten, Leipzig, 1927, pero los estudios de este tipo se renovaron a raíz de la publicación de WACKERNAGEL, R. H.: Der französische Krönungswagen von 1696-1825. Ein Beitrag zur Geschichte der repräsentativen Zeremonienswagens, Berlín, 1966. Su última aportación ha sido la coordinación de, Staats- und Galawagen der Wittelsbacher, Sttutgart, 2002, 2 vols. También se deben señalar, KUGLER, G.: The Golden Carriage of Prince Joseph Wenzel von Liechtenstein, Nueva York, 1985 y Die Wagenburg in Schönbrunn, Viena, 1996, así como HAUPT, H.: «Der «goldene Wagen» der österreichischen Herzogin Katharina (1420-1493)», Livrustkammaren. Journal of the Royal Armoury Stockholm, vol. XIV, 1976-1978, pp. 173-194, «Der Brautwagen der Königin Anna vom Jahre 1611. Ein Beitrag zur Geschichte des Festswagens und seiner Funktion im Hochzeitszeremoniell der frühen Neuzeit» y «Vom Kobelwagen zur Grand Carosse. Der Wagenbau im 17. Jahrhundert am Beispiel des fürstlich liechtensteinischen Fuhrparks», en Achse Rad und Wagen. Beiträge zur Geschicbte der Landfahrzenge, 1, 1991, pp. 21-25 y 4, 1996, pp. 8-15 respectivamente. Un intento de aproximarse a este tema de manera más amplia han sido los volúmenes dirigidos por ROCHE, D.: Les écuries royales du XVIe au XVIIIe siécle, París, 1998 y Voitures, chevaux et attelages du XVIe au XIXe siécle, París, 2000. Todos estos trabajos contienen amplias bibliografías que nos eximen de citarlas aquí detalladamente.

3 Por cierto, tradicionalmente desde la crítica cervantina. Sin ánimo de exhaustividad, véanse algunos comentarios de este tenor en las ediciones del Quijote llevadas a cabo por PeLlicer, J.A: Madrid, 1797, vol. IV, pp. 419 y ss; CLemencín, D.: Madrid, 1833-1839, vol. V, pp. 242-244 y RodríGuez Marín, Madrid, 1949, vol. X, pp. 102-111. Además, MONREAL, Julio: Cuadros viejos, Madrid, 1878, pp. 99-129; MARTín Del Olmo, A.: «Los coches en el Siglo de Oro», Historia y Vida, 113, 1977, pp. 61-73; FernándeZ OBlanCA, J.: «La pasión por los coches en el siglo XVII y su reflejo cómico en los entremeses barrocos», Archivum, t. XLI-XLII, 1991-1992, pp. 105-124; BRioso SANTOS, H.: «Vélez de Guevara y la sátira barroca: el tema de los encochados», en Bolaños Donoso P. y Martín OJeda, M.: Luis Vélez de Guevara y su época. IV Congreso de Historia de Écija, Sevilla, 1996, pp. 227-236 e IDEM, «Una nota socio-histórica a los capítulos 36 y 50 de la segunda parte del Quijote», Anales cervantinos, t. XXXIV, 1998, pp. 37-49. 
importantes cambios en el ceremonial y la etiqueta, en la imagen del señor y en sus hábitos y fueron medio se separar las calidades sociales, contribuyendo de forma inequívoca al cambio del caballero medieval al cortesano moderno. El análisis del fenómeno del uso del coche por tanto, no es una cuestión que tenga que ver de forma primordial con las corrientes artísticas, la historia de la técnica o la crítica de las costumbres sociales, en nuestra opinión ha de ocuparse ante todo de cómo este enser afectó a la configuración y a la representación del poder político entre los siglos XVI y XVII ${ }^{4}$. Precisamente por su estrecha relación con los cambios del poder político en la corte, es imprescindible discernir que evolución cronológica experimentó este proceso, pues de otra manera corre el riesgo de quedar desvinculado de la realidad social y no pasar de lo circunstancial ${ }^{5}$. De acuerdo a ello, hemos considerado tres periodos entre 1555 y 1700 que detallamos a continuación, haciendo especial hincapié a partir de 1600, cuando se produce la definitiva vinculación entre el coche y el cortesano.

\subsection{La introducción de los coches y los cambios en la caballeriza real y en la imagen del rey y del cortesano, 1555-1600}

La introducción de los coches en la corte hispana se fue afianzando paulatinamente desde aproximadamente 1555 en adelante, provocando importantes cambios en la caballeriza real y en la imagen del rey, que con el tiempo se fueron naturalizando también entre los cortesanos ${ }^{6}$.

Los reyes empezaron a utilizar los coches en Castilla en un momento en el que la caballeriza real experimentaba importantes cambios a raíz sobre todo, de

4 Así lo hemos tratado de demostrar en López Alvarez, A.: Poder, lujo y conflicto en la corte de los Austrias: coches, carrozas y sillas de mano, 1550-1700, Madrid, 2006, también en "Vehículos representativos en la Monarquía hispana de los siglos XVI y XVII», en GALÁN DomingO, E. (Coor.): Historia del carruaje en España, Madrid, 2005, pp. 120-149; "Kutschen und Sänften als Macht- und Statussymbole des spanischen Adels im 16.-18. Jahrhundert. Eine Beschreibung anhand zeitgenössischer Festberichte» y «Die Wagen der Habsburger Könige am Madrider Hof im 16. und 17. Jahrhundert», Achse Rad und Wagen, 7, 1999, pp. 20-29 y 10, 2002, pp. 16-29 respectivamente.

5 Así se percibe en varios, por lo demás excelentes trabajos, que se ocupan de enfrentamientos protocolarios con los carruajes como el de CALLADO ESTELA, E.: «Seis mulas para fray Pedro de Urbina. Un conflicto de preeminencias entre el arzobispo de Valencia y la Corona en el siglo XVII», Estudis, 29, 2003, pp. 179-190 y OCHOA BRUN, M. A.: «El incidente diplomático hispano-francés de $1661 »$, Boletín de la Real Academia de la Historia, t. CCI, 2004, pp. 97-159.

6 Un análisis detallado de toda esta evolución, que seguimos resumidamente, en LópEZ Álvarez, A.: "Organización y evolución de la caballeriza», en La Monarquía de Felipe II. La Casa del rey, vol. I, pp. 293-339. Puede verse también, IDEM, «La caballeriza del rey», en MARTíNEZ Millán, J.: (Dir.), La Corte de Felipe III y el gobierno de la Monarquía Católica, vol. I, La Casa Real, (en prensa) y LABrADOr ARroyo, F. y LÓpeZ AlvAREZ, A.: «Las caballerizas de las reinas en la Monarquía de los Austrias: cambios institucionales y evolución de las etiquetas, 1559-1611», en Studia Histórica. Historia Moderna, 28, (2006), pp. 87-140. 
la imposición de la etiqueta borgoñona y especialmente del asentamiento definitivo de la Corte (1561). Al mismo tiempo, este uso contribuyó a cambiar la planta de la caballeriza y las etiquetas y el ceremonial del monarca, modificando la forma en que el rey se presentaba en público. Así se determinó como habían de ocuparse sus asientos, el número de los que habían de salir en las diferentes ceremonias y cual debía ser su acompañamiento. Hacia 1585, culminando el proceso de institucionalización de la Monarquía, el coche sirvió sobre todo para ensalzar y alejar al rey, entonces se fijó el ceremonial para saludos y despedidas, salidas con el vehículo y acceso al zaguán de palacio, pero sobre todo, se iniciaron las entradas en coche, práctica que alteró las tradicionales entradas caballerescas, en caballo y bajo palio, propias de tiempos medievales.

Pero el uso del coche no solo afectó a la imagen del monarca, cambió también la del cortesano a través de un largo proceso. Ya al poco de su introducción en Castilla, las Cortes de Valladolid se quejaron de estos artefactos y pidieron su prohibición en 1555. Los procuradores se quejaban de que facilitaban la confusión estamental, el desorden moral, el aumento del lujo y la ruina económica, pero tras ello se vislumbraba que se movilizaban contra un nuevo y poderosísimo elemento de diferenciación social. En Cortes posteriores, así en 1573 y 1576 , los procuradores insistieron en pedir la prohibición de los coches porque se extendían sin control, necesitaban de muchos gastos, provocaban la carestía de las mulas y el abandono de la caballería.

En la línea de cambios políticos e ideológicos iniciados en la Monarquía de Felipe II desde 1560, se llevaron a cabo diversos procesos de reforma y disciplinamiento social que, dirigidos por la Junta de Reformación se acabaron ocupando también de los carruajes. Haciéndose eco de las peticiones en Cortes, el rey respondió en 1578 con una pragmática según la cual sólo se podía ir en coche o carroza llevando cuatro caballos propios, bajo pena de pérdida del vehículo, sus tiros y sus guarniciones. Quedaba permitido sin embargo, que unos y otros pudieran ir de camino (jornada de cinco leguas o más), con mulas o acémilas. La medida trataba de reducir su uso a la nobleza o a grupos sociales deseosos de ascender socialmente y con medios económicos, los únicos capaces de mantener ese nivel de gasto. Contrariamente a lo esperado, las Cortes olvidaron de repente todo lo que habían dicho en los últimos 20 años. Si ya antes ir en coche era muy oneroso, desde entonces, con cuatro caballos, era un gasto tan excesivo que las oligarquías urbanas no podían permitírselo, sobre todo teniendo en cuenta que los coches se habían convertido en una «necesidad, que esta tan introducida en estos reynos que ya no se puede excusar», como decían los procuradores. Estos suplicaron al rey que moderara la pragmática y nadie pudiera usar coche o carroza con más de uno o dos caballos. También pidieron que se prohibieran decoraciones lujosas en los vehículos y el uso de estos por la prostitutas. Resultado de estas quejas fue la pragmática en 1579 que prohibía ciertas decoraciones en los coches.

El giro de las Cortes se explicaba fácilmente: el coche quedaba vinculado de forma manifiesta a la nobleza que había de gobernar, a los cortesanos, como de 
facto ordenaba la pragmática. Las clases urbanas captaron perfectamente que este era un paso más en el proceso de exclusión del gobierno de la Monarquía. Su petición de coche barato significaba coche para ellos, para poder figurar entre las élites de la Monarquía, un coche a fin de cuentas, que no tradujera el proceso de institucionalización y consecuente diferenciación social que se estaba produciendo en ella ${ }^{7}$. La ley venía a subrayar que el lujo era necesario precisamente para distinguir los estamentos, para separar las calidades sociales, tratando de consolidar un orden socio-político. Según esto, había un lujo legítimo, propio de los privilegiados, ordenado y coherente con su preeminencia social. Este había de ser monopolio de la nobleza, como señal externa o atributo de su hegemonía.

De cualquier modo, y al socaire del periodo de acumulación monetaria de las últimas décadas del XVI, la competencia suntuaria favoreció y estimuló la compra de coches por parte de las élites ciudadanas. Su uso se extendió así entre licenciados, regidores, titulados y señores de vasallos. Frente a este aumento de los coches, fue necesario repetir la prohibición de 1578, proceso acentuado una vez más por las circunstancias políticas. El cambio en la forma de gobierno de la Monarquía, cristalizado desde mediados de los años 1580, mediante el cual la nobleza asumía un novedoso protagonismo, se tradujo en la consolidación del monopolio del coche en manos de esta, a fin de diferenciarla aun más como grupo social. Se dio entonces nueva pragmática en 1593 que extendía la obligación de llevar cuatro caballos a los llamados carricoches, unos novedosos vehículos con los que desde hacia años se burlaba la pragmática anterior ${ }^{8}$.

Con la llegada al trono de Felipe III en 1598, las restricciones al uso del coche fueron sacrificadas momentáneamente en aras de las necesidades de integración de la Monarquía. Se imponía un acercamiento de las élites urbanas para poder volver a reconstruir las redes clientelares imprescindibles para el funcionamiento del gobierno. Un permiso amplio en el uso de los vehículos iba a contribuir a ello, con el añadido de que no suponía desembolso alguno. Así, las peticiones de los procuradores en las primeras Cortes del reinado pidiendo coche barato de dos caballos, tuvieron éxito y en junio de 1600 salía una pragmática que permitía traer coches y carrozas con dos y cuatro caballos. La maniobra posponía las restricciones iniciadas dos décadas atrás y concitó crecientes críticas durante los diez años de existencia de la ley9.

7 A este respecto véase, MARTínez MilláN, J.: «La integración de las elites ciudadanas castellanas en la monarquía a través de la Casa real», en IDEM, La Monarquía de Felipe II. La Casa del rey, vol. I, pp. 645-697.

8 LóPez Álvarez, A.: voz «Carricoche», en Alvar, C. (coor.): Gran Enciclopedia Cervantina, (en prensa).

9 Las pragmáticas en Nueva Recopilación, Libro VI título XIX ley V, ley VII y ley VIII. Para las quejas de las Cortes, Actas de las Cortes de Castilla, Madrid, 1861-1991, en adelante Cortes vols. V (1 ${ }^{\text {a }}$ parte) pp. 176-177, 362-365; VII, p. 809; VIII, pp. 81, 92-97, 113, 173, 201-202; IX, pp. 35, 65-66, 210, 467-470; X, p. 329; XV, p. 739 y XVIII, pp. 248, 252 у 265-269. 


\subsection{La configuración del cortesano barroco, 1600-1630}

\subsubsection{La pragmática de las sillas, 1604}

Si bien es cierto que en 1600 el proceso de asimilación del coche y el cortesano sufrió un freno, no lo es menos que un par de años más tarde se ponía en marcha otro movimiento de menor entidad que presagiaba lo que había de venir en breve. Nos referimos a la institucionalización de las sillas de mano ${ }^{10}$, unos enseres que habían despertado mucho menos interés que los coches en las Cortes y en los círculos reformistas. En las Cortes celebradas en Madrid entre 1583 y 1585 se responsabilizó de su proliferación a la obligación de llevar coches con cuatro caballos, pidiendo los procuradores a Felipe II que las mandara «probibir y vedar», aunque sin ningún resultado positivo ${ }^{11}$. En 1594 y 1601, se dieron medidas para controlar el número de los silleteros y sus precios, lo que muestra que su uso había aumentado considerablemente. También se criticó su lujo excesivo, lo que condujo a que el 2 de enero de 1600 Felipe III diera pragmática por la que se prohibían ciertas decoraciones en ellas ${ }^{12}$. La culminación de todas estas medidas fue la pragmática de 1604, una ley destinada a restringir un enser de lujo que se había extendido demasiado, potenciar la caballería y limpiar el espacio social de la corte. Pero sobre todo, la pragmática institucionalizaba el uso de la silla al ordenar que ningún hombre pudiera servirse de ellas sin tener licencia del rey, bajo pena de pérdida de la silla y 20.000 mrs. de multa ${ }^{13}$. La prohibición tuvo como consecuencia que numerosos personajes solicitaran la correspondiente licencia al Consejo de Castilla. Estas fueron

10 Para la evolución experimentada en el uso de las sillas y los problemas con los silleteros de la corte, véase López Alvarez, A.: voz «silla de manos» en Alvar, C. (coor.): Gran Enciclopedia Cervantina, (en prensa).

11 La contestación del monarca era que se mandaría «mirar para proveher lo que convenga», Cortes, vol. VII, p. 834. § LXV. En 1598 las Cortes volvieron a ocuparse del asunto, idem, vol. XV, p. 766.

12 En un billete de primeros de octubre de 1599 se pedía que en la reforma suntuaria que se avecinaba se moderaran las sillas «de modo q no puedan tener tela de oro ni de pta ni bilo fino ni falso ni ser bordadas», BNM Mss. 2346, f. 65. La pragmática prohibió construir sillas «de brocado, ni tela de oro, o plata, ni de seda alguna que lo lleve; ni puedan ser bordados los aforros de ellas de cosa alguna, y no se puedan hacer sino de terciopelo, o damasco, o otra qualquier seda; y puedan llevar flocaduras, y alamares de ella, y no de oro, ni plata; y los pilares de las dichas sillas puedan ser guarnecidos de pasamanos de seda, y tachuelas", véase Nueva Recopilación, Libro VII, título XII, ley II, cap. 4.

13 Nueva Recopilación, Libro VII, título XII, ley VIII. El razonamiento de los consejeros justificaba la prohibición partiendo de que además de «otros inconvenientes» que se podían seguir, se había visto «el excesso y desorden que ay en andar en silla de mano los hombres de todas las edades, sin necesidad, ni otra causa alguna, por solo su regalo, que de pocos años a esta parte se a introduzido, siendo cosa tan indecente, y que por ello se va olvidando el loable y necesario exercicio de los cavallos». Prematica en que se probibe andar a los hombres en silla de mano, BNM VE 40-75. Además, cabe destacar un intento de definir la silla como un elemento suntuario propiamente femenino, muy vinculado a la imagen de la reina, que por entonces hacía uso frecuentemente de ellas, véase, LABrADOR Arroyo, F. y LóPEZ ÁlvarEZ, A.: «Las caballerizas de las reinas en la Monarquía de los Austrias...», pp. 132, 133, 137 y 138. 
a parar en su mayoría a manos de criados del rey, miembros de los Tribunales y Consejos y aristócratas de la corte. De esta manera, se premiaban fidelidades sin gasto, se reforzaban las redes clientelares y se contribuía a homogeneizar a los cortesanos y separarlos de quienes no lo eran, aunque también provocaran a la postre cierta tendencia a la competencia suntuaria ${ }^{14}$.

\subsubsection{La institucionalización del uso del coche, 1611-1630}

El proceso de reformación —como se decía entonces- que se abrió a partir de 1611 mediante la pragmática de enero de ese año, fue una maniobra radical de importantes consecuencias que buscó enlazar de forma inseparable el coche con el cortesano y conformar una nueva distinción social al permitirlo sólo a quienes lograran una licencia del Consejo de Castilla, proceso que hemos denominado institucionalización. Según la prolija ley, quedaba prohibido hacer carruajes de nuevo sin licencia del Presidente de Consejo y se ordenaba el registro de los existentes. Se prohibía a cualquier hombre ir en coche sin previa licencia del rey, aunque se permitía que las mujeres pudieran hacerlo yendo destapadas, de manera que pudieran ser reconocidas, pero con la condición de que el vehículo fuera propio y llevara cuatro caballos. Las mujeres podían llevar en sus coches a sus maridos, padres, hijos y abuelos y a las mujeres que quisieren, yendo con ellos, pero sus hijas, deudas o criadas podían ir solas. También se permitía a los hombres que tuvieren licencia que pudieran llevar en sus coches a los hombres que quisieren, yendo ellos dentro. Se prohibía prestar los coches, se prohibía también a los que lo tuvieran venderlo, trocarlo o enajenarlo sin licencia del Presidente del Consejo y, con la intención de evitar a toda costa este uso por quienes no lo merecían, se prohibía también ruar en coche alquilado en la corte, todo ello bajo fuertes penas. Todas las disposiciones mencionadas se entendían con los carricoches y cualquier otro género de vehículos que se hicieran. En cuanto a las prostitutas, se les prohibió el uso de coche, carroza, litera o silla de manos so pena de cuatro años de destierro de donde hubieran sido denunciadas por la primera vez, y de destierro y ser traídas a la vergüenza públicamente, por la segunda ${ }^{15}$.

14 Véase el caso de los contadores. A mediados de 1610, en la consulta del memorial de Diego Pérez de Salcedo, se informaba que éste solicitaba que le fuera concedida la licencia como se había hecho con Gabriel de Santa Cruz, Sancho Méndez de Salazar contadores de la Contaduría mayor y con Pedro Luis de Torregrosa contador de la Caja. El primero de ellos había sido, el 8 de diciembre de 1605, Luis de Torregrosa, a quien se concedió licencia sin límite de tiempo, AHN Consejos Leg. 4417/ 197. El 4 de agosto de 1607 Gabriel de Santa Cruz la obtuvo por dos años y, al mes siguiente, el 3 de septiembre fue Sancho Méndez de Salazar el que la recibió por tres años, AHN Consejos Leg. 4418/156 y 178 respectivamente. Aunque la Cámara reconocía que se tenía mucho la mano en consultar estas licencias y que sólo se daban, aunque las pedían muchos, a gente de «mucha calidad y q tenga precisa necesidad dellas», fue de la opinión que se le diera también a Diego Pérez de Salcedo, AHN Consejos Leg. 4419/ 56.

15 La pragmática en Nueva Recopilación Libro VI título XIX ley IX. 
A los pocos meses fue necesario detallar la ley. Había habido bastantes malentendidos que llevaron a dar una aclaración que explicaba mejor sus límites y restringía más el uso del coche. Así, el 4 de abril, se recordaba la prohibición de andar en coches prestados, pero se reconocía que en su execución y declaracion han resultado algunas dudas", por lo que se mandaba que no yendo los dueños de los coches en ellos pudiesen ir las deudas de las familias, pero «para este efecto se entienda ser deudas de la familia solamente las que vivieren y comieren de ordinario a costa de cuyo fuere el coche». Los hombres que tenían licencias podían llevar en el coche «a los que quisieren» siendo hombres, pero siendo mujeres se ordenaba que «sea solamente a sus mugeres propias, madres, abuelas, hijas, suegras y nueras». En esa misma línea, se permitía que los hijos de quienes tenían licencia para ir en coche «puedan andar en ellos, aunque los padres no vayan dentro, hasta edad de diez años y no mas».

Del mismo modo que estaba prohibido prestar los coches, se prohibía prestar caballos para andar en ellos. Con respecto a la prohibición de andar en coches ajenos por la que se ordenaba que nadie pudiera ir en vehículo «que no sea suyo", se aclaraba que eso "no se entienda con nuestros criados que por razon de sus oficios les tocare». También se ampliaba la prohibición de ruar en coche alquilado en la corte ordenándose que «lo mismo se entienda en todas las ciudades, villas y lugares de estos nuestros Reynos». Por último, se aclaraba que se podía ir de camino, es decir salir de viaje, en coche de mulas ya fuera propio o alquilado «aunque sea de cinco leguas abaxo, y aunque sea prestado para el camino» ${ }^{16}$.

La pragmática y su ampliación o aclaración tenían como objetivo el estricto monopolio del coche por parte de las elites que gobernaban la Monarquía, es decir, la aristocracia cortesana, los ministros y criados de la Casa real, los altos eclesiásticos y quienes tuvieran estrechas relaciones con ellos en los grandes centros urbanos. En consecuencia, las licencias se dieron a todos los presidentes de los Consejos, a todos los consejeros y a todos los fiscales y secretarios, a quienes se permitía «andar en coches de dos caballos con sus mujeres». El mismo privilegio alcanzaron los médicos de cámara del rey y todos los embajadores. Junto a estos, que eran varios centenares, se dieron licencias a un buen número de titulados, la mayor parte de los cuales podía circular en coche de cuatro caballos. Entre ellos los más cercanos al duque de Lerma; el conde de Villaflor mayordomo del rey, don Diego de Guzmán limosnero mayor, el marqués de la Laguna mayordomo mayor de la reina así como el duque de Uceda y el marqués de Villafranca, hijo y favorito del valido respectivamente. También cuatro caballos podían traer el conde de Medellín mayordomo del rey, el marqués de Malpica gentilhombre de la cámara, el conde de Villamediana, el duque de Cea, el de Alba, el de Feria, el de Pastrana, el de Sessa, el de Peñaranda o el de Medinaceli. A ellos se unieron predicadores y capellanes reales, los más destacados banqueros de la corte y algunos otros criados de las Casas reales, como

16 Nueva Recopilación, Libro VII, título XII, ley VI. 
gentilhombres. Tras estos se dieron licencias para coches de dos caballos a las viudas de ministros y consejeros muertos en el servicio al rey y a algunos familiares cercanos de todos estos personajes.

También se dieron licencias a las mas altas jerarquías eclesiásticas, como los obispos, a quienes se les concedió para coche de cuatro caballos. De la misma forma, la tuvieron los miembros de los Tribunales del Santo Oficio de la Inquisición diseminados por Castilla y los presidentes y miembros de los Tribunales y Audiencias de Sevilla, Valladolid y Granada, ciudades que, por albergar los tribunales reales, eran corte a todos los efectos. Fuera de esta, quienes disfrutaron de semejante privilegio fueron personajes con influencias en ella, como deanes y arcedianos de los capítulos eclesiásticos y destacados canónigos de las catedrales castellanas. También alcanzaron licencias algunos regidores de las grandes ciudades del reino, así como aristócratas locales, señores de vasallos, caballeros de Órdenes Militares y los procuradores de las 18 ciudades con representación en Cortes.

Al privilegio de usar el coche se unió el de hacerlo de la manera más barata posible porque la inmensa mayoría de los que pedían licencias lo hacían para coche de dos caballos y quienes la obtenían para de cuatro caballos (unos 250 personajes entre 1611-1621, de los cuales 200 el primer año) la solicitaban inmediatamente para poder llevarlo con dos, concediéndoseles en su mayoría, porque mantener cuatro animales era una excesiva carga, como argumentaron repetidas veces. Fue así como ya desde el comienzo se alteró el sentido inicial de la ley.

La concesión de las licencias alcanzó la cifra media anual de unas 150 entre 1612 y 1617, pero desde principios de 1618, en paralelo al importante impulso reformador acaecido en los últimos años del reinado de Felipe III, el panorama cambió radicalmente. La detención resulta palpable; medio centenar de licencias en 1618, unas cuatro al año siguiente, siete en 1620 y ninguna en 1621. Con la llegada de Felipe IV al trono en 1621 volvió a abrirse la espita de las licencias y en 1622 y 1623 se dieron casi tantas como en los años de la década anterior. Pero a la postre, la restricción se impuso: desde 1625 la caída fue muy significativa y las licencias fueron paulatinamente a su desaparición hasta convertirse después de 1630 en una rareza.

Fueron muchas y diversas las consecuencias que tuvo este proceso en la Monarquía. A nuestro juicio, lo más relevante de la institucionalización es que cargó de sentido político el uso del coche y modificó los códigos de comportamiento cortesanos, como el ocio, el galanteo, los gastos suntuarios o el ceremonial. Para calibrar de alguna manera el alcance del fenómeno, baste decir que hasta 1621 se dieron unas 2300 licencias que pudieron llegar a permitir el uso del coche a unas 3000 personas en toda Castilla, de ellas, cerca de 1000 el mismo año de 1611. De esta forma, la institucionalización del uso del coche no sólo no disminuyó el número de los que lo usaban (objetivo que se había argumentado siempre que se ponían en marcha reformas suntuarias), sino que lo aumentó entre dos y cuatro veces, proceso que, creemos, no tuvo parangón en 
ninguna corte de Europa y es una muestra del esplendor que por entonces alcanzaba la Monarquía hispana ${ }^{17}$. No es necesario decir que ello provocó numerosos y continuados intentos de lograr licencias o ir en coche en aquellos grupos sociales que habían sido excluidos de este privilegio.

\subsubsection{Las pragmáticas de 1619, 1628 y 1632. El problema de la agricul- tura y las mulas}

Entre los que protagonizaron los intentos mas significativos de ir en coche estuvieron los labradores y las élites urbanas que no se habían visto satisfechas con el proceso de las licencias, un sistema que, en boca de los procuradores «solo sirve a negociaciones particulares y no al beneficio comun» ${ }^{18}$. Los labradores y sus representantes en las Cortes clamaron pronto por tener coche más fácilmente, vinculando este privilegio al aumento de la producción agrícola, logrando que se diera la pragmática de 1619 por la que se permitía llevar coche de mulas fuera de la corte a quienes labraran 25 fanegas.

Esta ley ha de ponerse en relación con una importante corriente de pensamiento surgida a finales de los años 70 del siglo XVI y que duró hasta finales del primer cuarto del siglo siguiente, que se preocupó profundamente por el problema agrario ${ }^{19}$. Además del natural interés por el aumento de la producción, también se alzaron voces que clamaron por la dignificación y por la nobilización del campesino. Desde bien temprano, el coche había sido considerado como un posible estímulo en este sentido, pues se propuso permitir su uso a quien plantara ciertas cantidades de trigo ${ }^{20}$. Fue esta una idea que las Cortes acabaron por retomar, logrando que entre las condiciones dispuestas para la concesión del servicio de los millones en 1619, se incluyera una por la que se permitía a cualquier persona andar en coche de mulas labrando 25 fanegas de

17 Los memoriales pidiendo las licencias para el periodo 1611-1621, las deliberaciones de la Cámara de Castilla y la concesión final se encuentran en AGS CC Legs. 990-1100 y AGS CC Libros 178-195. También hay que consultar, AHN Consejos Leg. 4419-4428 y Legs. 13.192-13.204. Las licencias dadas no se corresponden exactamente con los que podían ir en coche porque, muy frecuentemente, no especificaban exactamente cuantos familiares se incluían en ellas, señalándose simplemente que se extendían para la mujer y a los hijos que vivieran bajo un mismo techo. Un análisis parcial de este proceso en LÓPEZ ÁlVAREZ, A.: «El cortesano barroco: la institucionalización del coche y las licencias para su uso (el caso de Murcia, 1611-1621)", comunicación presentada al Congreso Internacional, Las elites en la época Moderna: La Monarquía española, celebrado en octubre de 2006 en Córdoba.

18 Cortes, vol. XXXI, pp. 402-404. La fecha fue 28 de marzo de 1618.

19 GUTIÉRREZ NiETO, J.I.: «El pensamiento económico, político y social de los arbistristas», en Ramón Menéndez Pidal. Historia de España, t. XXVI, pp. 233-351, especialmente, pp. 299 y ss.

20 Así se aprecia en la famosa Relación de los corregidores de Castilla, compuesta en 1583, inclusa en VIÑAS Y MEY, C.: El problema de la tierra en la España de los siglos XVI y XVII, Madrid, 1941, pp. 218 y 226. 
tierra, petición que se convirtió en ley ese mismo año ${ }^{21}$. La maniobra tuvo como consecuencia que la reforma de los coches quedara vinculada a los avatares de las condiciones de millones y más significativamente aun, que se creara un nuevo grupo de privilegiados cuyo status fue rápidamente criticado y cuyo ejemplo se tardó poquísimo en seguir, volviéndose a desvirtuar el contenido de la pragmática de 1611 .

Efectivamente, otro aspecto de la pragmática de 1611 que conoció cambios fue el uso de las mulas en los coches, que estaba prohibido en Castilla desde 1578. Su resistencia, su fuerza y su facilidad para ser usadas en los carruajes, les llevó a ser muy estimadas y a reemplazar con el tiempo a los caballos como animal de tiro, aunque no sin funestas consecuencias según mantenían algunos. Estas circunstancias, junto al hecho de que se hubiera abierto la mano en el uso de las mulas beneficiando a los labradores, impulsaron a los cortesanos a la búsqueda de un coche más barato. Así, desde comienzos de 1622, se empezaron a dar licencias para llevar mulas en el coche a los mayordomos del rey, títulos, médicos, secretarios, miembros de los Consejos, obispos y otros personajes ${ }^{22}$. Abierta la espita, los intentos de ir en coche de mulas se sucedieron continuadamente.

A finales de los años 1620 parecía adivinarse que ni la agricultura se estaba adelantando todo lo esperado a raíz de la pragmática de 1619, ni la prohibición de ir en coches de mulas se obedecía, de hecho estas se extendían novedosa-

21 Peticiones en este sentido había tenido lugar en las Cortes de 1592-1598, en las de 16021604 y sobre todo en 1617-1620, véase Cortes, vol. XVI, p. 638; XXI, pp. 380-381; XXII, pp. 375 y 445; XXX, pp. 337-338; XXXI, pp. 400-404 y XXXII, pp. 78-79 y 538. La pragmática en Nueva Recopilación Libro VI título XIX ley X. La cédula dada en Belem, el 8 de junio de 1619, en BNM R 31763/ 55.

22 Véanse entre otros casos el del almirante de Aragón, consulta del 23-I-1622, AHN Consejos Leg. 4422/16; el conde de Monterrey, el príncipe de Esquilache y el doctor Garçon médico de la familia de la reina, en la consulta del 9-XI-1624, Leg. 4423/185. Don Juan Portocarrero conde de Medellín, pidió licencia para coche de mulas porque tenía una hacienda en Canillejas a una legua de la corte, consulta del 19-IV-1625, Leg. 4423/81. También lo hicieron el marqués de la Hinojosa del Consejo de Estado y presidente de Indias, consulta del 19-IX-1626 Leg. 4423/113, el duque de Pastrana cazador mayor, consulta del 2-X-1626, Leg. 13193-75, el marqués de Aytona del Consejo de Estado, consulta del 8-VII-1624, Leg. 13192-8 (50). El doctor Antonio de Santa Cruz pedía licencia de coche de dos mulas como se había hecho con sus compañeros el doctor Mercado, el doctor Valle y el doctor Ruiz, consulta del 20-VI-1620, AHN Consejos Leg. 4421/78. El doctor Alonso Romano cirujano de cámara pedía licencia para coche de mulas porque tenía labranza, en Móstoles consulta del 30-VIII-1625, Leg. 4423/176 y también la pedía el doctor Francisco de Herrera, consulta del 24-X-1626, Leg. 4423/137. El obispo de Oviedo pedía licencia para coche con mulas por «la aspereşa de la tierra y falta de mantenimiento para cavallos», consulta del 27-II-1622, AHN Consejos Leg. 4422/45. El obispo de León adujo parecidas razones, consulta del 5-II-1623, Leg. 4422/21, mientras el obispo de Zamora la pidió para poder gastar en los pobres lo que ahorraba en caballos, consulta del 22-II-1625, Leg. 4423/70. Véanse también los casos del obispo de Badajoz, consulta del 27-IV-1622, Leg. 4422/90, el arzobispo de México, que pidió licencia para traer mulas en sus carrozas en la corte, consulta del 4-X-1624, Leg. 13192-9 (84) y el Patriarca de las Indias, consulta del 3-II-1623, Leg. 4422/18. 
mente. El debate sobre el uso de las mulas en los coches volvió nuevamente a la palestra: unos abogaban por dejar que los labradores pudieran seguir teniendo coches de mulas, otros querían eliminar los coches de los labradores completamente. Ambas posturas chocaron en 1627 y solo tras complicadas negociaciones en las Cortes, en 1628, se prohibió ir en coche de rúa con dos, cuatro o seis mulas. Únicamente se permitía ir en coche de mulas para distancias inferiores a cinco leguas yendo de camino, o sea, de viaje, so pena de pérdida de los carruajes, las mulas y sus aderezos y $50.000 \mathrm{mrs}$. Ningún cochero podría traer coche de mulas so pena de destierro por un año por la primera vez y de dos años por la segunda ${ }^{23}$.

A pesar de la disposición, el uso de estos animales no se frenó y con la autoridad que había de dar la denuncia de numerosas irregularidades, las Cortes no cesaron de pretender que se modificara la ley, cosa que lograron en poco tiempo, pendientes como estaban los millones. Ya en octubre de 1629, el monarca aceptó que los que labraran 25 fanegas pudieran tener coches de mulas en cualquier lugar del reino salvo en la corte, es decir, se volvía a la pragmática de 1619 y se derogaba la de 1628, tan sólo un año después de su publicación. Aunque la nueva pragmática no fue dada hasta las Cortes de $1632^{24}$, parece que su contenido estuvo vigente desde 1629, facilitando a las élites urbanas usar de coche con mulas y dando alas a la emulación de los cortesanos que pretendían lo mismo, con harto peligro de echar a pique las restricciones ${ }^{25}$. La maniobra mostraba una vez más que, frente a la más estricta ley, acababan apareciendo nuevos espacios de privilegio que, a la vez que distanciaban a sus beneficiarios de la mayoría, invitaban a otros a seguir su ejemplo. Así, el uso de mulas en los coches se extendió desde entonces y acabó sustituyendo con el tiempo al de los caballos.

\subsubsection{Los excluidos del coche, conflictos y probibiciones}

La institucionalización del uso del coche estableció una estricta separación entre los que podían usarlo, los cortesanos y sus familiares, y los que no. Desde entonces, el deseo de formar parte de esa nueva y visible élite llevó a muchos a consagrar no pocos esfuerzos en lograr una licencia, a otros en montar en coche

23 Cortes, vols. XLV, pp. 428, 495-496; XLVI, pp. 338, 344-345, 350-351, 362 y XLVII, pp. 91, 144-145 y 156. Otros aspectos de la discusión en AHN Consejos Leg. 51438/1. Para la pragmática, Premática y ley, que su Magestad ba mandado promulgar, y que se guarde, para que nayde traiga mulas en coche, Nueva Recopilación Libro VI título XIX ley XI.

24 Cortes, vols. XLVII, pp. 331-334, 408-409, 429-430 y 448-451; L, pp. 143 y 225 y LI, pp. 67-68 y 353-354. La pragmática en Nueva Recopilación Libro VI título XIX ley XII.

25 Efectivamente, numerosos personajes pidieron en las Cortes ser eximidos de esta ley, véanse las discusiones y las dispensas en Cortes, vols. XLVIII, pp. 161-163, 366-367; LII, pp. 202-203, 213, 311, 345, 396-399, 420, 438-439; LIII, pp. 124, 127, 140, 155-156, 219, 277, 355, 392 у LIV, pp. 81, 336-337, 339-340, 346-347, 380 у 464. 
sin ella y a unos terceros, los que ya la poseían, a impedir este acceso en la medida de lo posible, entre otras razones, para no desvirtuar el aprecio social del carruaje.

Desde 1611 fueron excluidos de forma sistemática de las licencias escribanos, alguaciles, mercaderes, oficiales de manos y prostitutas, profesores y estudiantes. Tampoco los alcaldes de Casa y corte ni los corregidores de Castilla, ambos oficios por cierto muy cercanos a los consejeros, obtuvieron licencias, aunque si sus mujeres. Pero la reforma de los coches también se plasmó en las restricciones que se dieron en varias ciudades, como en Vitoria y Málaga ${ }^{26}$ y sobre todo en dos de las más grandes del reino, Sevilla y Granada. Estos últimos casos son muy relevantes no sólo porque junto a Madrid y Valladolid, eran las únicas de la Monarquía con «numero grande de coches», sino sobre todo, porque en ellas residían tribunales del rey y en consecuencia, eran corte.

En Sevilla los enfrentamientos más significativos tuvieron lugar en el seno del concejo, constituido por veinticuatros y jurados. Los veinticuatros eran social y económicamente superiores a los jurados, quienes presionaron en distintas ocasiones para que los igualaran social y jurídicamente a los otros, sin que nunca lo llegaran a conseguir. A partir de 1611, el coche fue un argumento contundente, quizás la muestra definitiva de la soñada igualdad en la diferencia. Por de pronto, los jurados lograron que se dieran muy pocas licencias argumentando que en los coches se defraudaba a la hacienda real y que los vehículos hacían gran daño a las conducciones de agua de la ciudad ${ }^{27}$. El Consejo de Castilla se hizo eco de la denuncia y apenas si concedió licencias en Sevilla, de hecho, la abrumadora mayoría de las dadas excluían expresamente la ciudad andaluza ${ }^{28}$. La radicalidad de la restricción sevillana se aprecia claramente en una anécdota que recuerda los dicterios literarios contemporáneos. Gómez de Figueroa, caballero residente en la ciudad, escribía en enero de 1613 a don Diego Sarmiento, conocido más tarde como conde de Gondomar, informándole que se casaba con una mujer de saneada hacienda y pidiendo le consiguiera una licencia: «... yo no tengo galas que darle a mi muger y estimare como la bida darle una $q$ es una lisençia para que pueda rodar aqui su coche con dos caballos». Pero el papelito se dilataba, obligándole en abril a escribir a don Diego:

26 La prohibición de ir en coche en Vitoria, solicitada por la villa misma, se inició en 1621 y se renovó en 1687, véase AHN Consejos Leg. 4424/65, Leg. 4427/169 y AMV 8-2-16 y 17. La prohibición malagueña, debida a los ataques berberiscos a los que no se podía hacer frente con caballeros habituados al ocio de los coches en lugar de a los caballos, se extendió al menos entre 1622 y 1639, AHN Consejos Leg. 4422/90 y Leg. 4427/169. Con todo, en Málaga se dieron unas pocas licencias en esos años, véanse algunos de ellos en AGS CC Libro 179, f. 459, Libro 181, f. $33 \mathrm{v}$, Libro $182 \mathrm{ff} .33 \mathrm{v}, 67 \mathrm{v}, 71$ y 483.

27 AHN Consejos Leg. 4419/52, 165, 168 y 172.

28 El 28 de agosto de 1611 la Cámara apuntaba que «en todas las liçençias que se dieren se ponga que se pueda usar dellas en todo el reyno exepto en Sevilla», AHN Consejos Leg. 4419/172. Algunas de las concedidas estos años en la ciudad en AGS CC Libro 178 ff. 325, 339, 381; Libro 179 ff. 199, 236v, 270v; Libro 181 f. 131v; Libro 183 f. 139 y Libro 186 f. 277v. 
Prometto a VS que estimare en ttanto la licençia del coche como si el Rey me diera una encomienda y assi sera la mayor mcd que VS Pueda hazerme ${ }^{29}$.

Las maquinaciones de los jurados dieron una vuelta de tuerca a la situación y en 1614 se prohibió definitivamente ruar coche en Sevilla. Después de unos meses, el Ayuntamiento, el cabildo de la catedral y otros personajes e instituciones trataron por todos los medios de que se les volvieran a conceder licencias. Tantas fueron las quejas y tanto argumentaron, que el mismo Consejo de Castilla pidió al rey suavizar la prohibición:

por no desconsolar a Sevilla y desigualarla tanto de las otras Çiudades sirviendo como sirve siempre a VMd con tanta demostraçion en las occasiones q se ofrezen convendria conçeder algunas Liçençias de coches a quien lo meresca como son a los grandes y titulados que residen en aquella Çiudad y algunas dignidades y personas ecclesiasticas y otras que por su calidad y justos impedimientos pareçiese que se les podria conceder y de quien se tenga satisfacion que no haran fraude ni usaran de las dhas liçençias en deservicio de $\mathrm{VMd}^{30}$.

El rey respondió que se diera licencia a los grandes y títulos que vivían en Sevilla, al cabildo de la iglesia mayor, a los veinticuatros, jurados, al presidente y jueces de la Audiencia, al presidente de la Casa de Contratación y a los inquisidores, pero que tras ellos no se diera a nadie más. La noticia debió correr en Sevilla como la pólvora, pero esta vez fueron los veinticuatros quienes cortocircuitaron las licencias para los jurados y pidieron que les fueran denegadas. Así las cosas, estos se quejaron al Consejo asegurando que la detención de su licencia, era

con gran nota de sus personas y mengua de la autoridad de sus oficios, en daño del bien publico y del servicio de V.M.d .... y que si ay diferencia entre ellos es solo en el nombre; ... y que el oficio de jurado siempre lo a exercido gente lucida y rica y los naturales y de las familias mas antiguas, de suerte que entre los $24^{\circ}$ s y ellos la principal diferencia a sido que el de $24^{\circ} \mathrm{s}$ supone mas riqueza y ansi muchos jurados que han crecido en hazienda, o sus hijos, acomodan las juradurías y entran en oficios de $24^{\circ}$ s y Alcaldes Mayores y lo que mas es, el de jurado da nobleza.

A pesar de todo, la Cámara fue de la opinión que se excusara el dar licencia general a los jurados, «sino que quando ellos y algunos otros cavalleros de aquella çiudad la pidiesen en particular y fuesen de calidad, que fuese justo el darsela, se conçediesse». El monarca cedió, los jurados no tendrían coche como tales, sino de forma individual, si lo merecían. No fue así, y como tuvieron poco éxito en ello volvieron a pedir licencia en común, aunque su aspiración volvió a ser rechaza-

29 Las jugosas cartas de Gómez de Figueroa en BPR II/ 2142 doc. 138, II/ 2179 doc. 146; II/ 2129 doc. 199bis, doc. 200 y doc. 216.

30 AHN Consejos Leg. 4420/75. La cédula real con la prohibición en AGS CC Libro 181 f. 317. 
da en $1623^{31}$. Con todo, el enfrentamiento más radical que tuvieron ambos grupos por el uso del coche tuvo lugar a raíz de las inundaciones de 1626, cuando la situación se volvió favorable a ojos de los jurados para devolver a los veinticuatros la última humillación - la negativa a sus licencias de 1623debido a las terribles inundaciones que dejaron la ciudad impracticable durante meses, hasta el punto de que la propuesta de prohibir los coches se volvía más verosímil que nunca; nadie podría usar el coche en Sevilla.

El ambiente era propicio, entre otras cosas porque, aun sin inundación, las calles de la ciudad se hallaban imposibles para el trasiego que debían sostener, en buena parte debido al estado de los empedrados, uno de los problemas que los jurados denunciaban hacía años. A pesar de algunos avances en la pavimentación de las calles, el mal estado de las vías sevillanas era un lugar común ${ }^{32}$. La inundación empeoró radicalmente las cosas y los jurados aprovecharon sus efectos para pedir al Consejo la prohibición de ruar los coches en la ciudad, que lograron. La prohibición cayó como un rayo en el concejo, donde los debates fueron muy tensos. Entretanto, en el Consejo de Castilla se acopiaron pruebas para prorrogar la prohibición o acabarla. Partidarios de la prohibición y contrarios a ella, jugaron sus cartas e hicieron uso de sus relaciones. Para los veinticuatros, la razón por la que los jurados habían solicitado la prohibición era el no poder tener coche ellos. Don Juan de la Sal, obispo de Bona, partidario de eliminarlos, denunciaba por su parte además del mal estado de las calles, que las familias se gastaban las haciendas por tenerlos y el clima moral de la ciudad estaba muy degradado. La prohibición volvió a prorrogarse y las discusiones en el concejo a repetirse, derivando a la cuestión de arreglar el empedrado. En ellas acabó terciando el Asistente quien, deseoso de hurtar este debate, recordaba que la proposición hecha iba «en horden a la salud publica desta ciudad y en especial de la gente mas granada de ella que son los que usan coches». Insistía en que el calor en Sevilla durante los meses de verano era «el mas dañoso de todo el reino y el daño de las enfermedades yrreparable» y que prohibir los coches mientras tanto «solo servira... de morir o enfermar mucha gente principal y honrrada desta ciudad». Finalmente, la prohibición de los coches estuvo en vigor durante largos me$\operatorname{ses}^{33}$. Los jurados lograron así una victoria notoria, aunque momentánea, que

31 Véase GonZÁlez Palencia, A.: La Junta de Reformación, Valladolid, 1932, pp. 475-477. Aquí las citas. También AHN Consejos Leg. $4420 / 75$ y 141. Peticiones de jurados denegadas en AGS CC Leg. 1042/65 y 1044/sf.

32 Albardonero Freire, A.J.: El urbanismo en Sevilla durante el reinado de Felipe II, Sevilla, 2002, pp. 345-356. Para las quejas de los jurados, GonZÁlez PALENCIA: La Junta de reformación, pp. 190-191.

33 Para las discusiones en Sevilla AMS Actas Capitulares, 1626, $1^{\text {a }}$ escribanía, vol. 37 sf. y $16262^{\mathrm{a}}$ escribanía vol. 110 sf. Para las opiniones del obispo de Bona, BonNEviLLE, H.: «Dos testimonios inéditos de don Juan de la Sal, Obispo de Bona, sobre la vida en Sevilla (1623 y 1626)», en AA.VV., Hommage des hispanistes français a Noel Salomon, Barcelona, 1979, pp. 118-121. Para el contexto general es imprescindible la obra de Brochero, L.: Discurso problemático del uso de los coches. 
dejaba traslucir cuanto de privilegio, de exclusividad, había en el uso del coche. El debate sevillano manifestaba también lo esencial que era para los excluidos poder poner en cuestión esta situación de privilegio y por un tiempo, lograr desvanecer éste. El episodio era prueba en fin, de las profundas tensiones que el uso del coche generaba en la sociedad cortesana y la importancia que este tenía como elemento de prestigio.

Las primeras noticias sobre problemas con los coches en Granada datan de 1618 cuando los enfrentamientos por su uso estallaron en el concejo. Habían sido numerosos los personajes que habían recibido licencia de coche en la ciudad en aquellos años, no menos de 90 hasta 1618. Entre los agraciados destacaban netamente los veinticuatros ${ }^{34}$. Tanto la cantidad como la acumulación de licencias en unos pocos años y el que buena parte de ellas fueran a parar a los veinticuatros y sus familiares, eran razones suficientes para que las incomodidades por el uso de los coches se multiplicaran tanto en el plano de la convivencia urbana, como en el plano de lo simbólico.

Como en otras ciudades, el uso del coche había creado una capa diferenciada cuya preeminencia no era muy bien vista por aquellos que muy cercanos socialmente a los anteriores, no la disfrutaban. Además, dado el peculiar urbanismo de la ciudad, provocaba numerosos problemas protocolarios entre los de la Chancillería y los caballeros. En este contexto, el Ayuntamiento se dividió en dos, los que querían mantener el uso del coche y los que no lo tenían y estaban en contra, los cuales, aduciendo razones muy diversas, propusieron su prohibición en 1618. Las causas fundamentales para solicitarla eran el efecto negativo sobre la cría de caballos y la pérdida de la caballería, que no había animales para acudir al servicio del rey, que los caballeros se empeñaban económicamente y que los coches afectaban a la higiene y salud pública de la ciudad porque destruían, como en Sevilla, los encañados de la ciudad. En voto secreto entre los miembros del concejo que no tenían coche, se decidió que se quitaran estos de la ciudad ${ }^{35}$. Aunque por el momento la petición no tuvo el eco deseado, la polémica granadina se reactivó a partir de 1621 al acceder al trono Felipe IV, cuando el debate subió de tono y diversos personajes escribieron opúsculos a favor y en contra sobre todo, del uso de los coches. Entre aquellos estuvo Francisco Porcel, quien dio a las prensas una obrita titulada Pide el bulgo no aya coches en la que exponía las razones que había para prohibir el uso de los vehículos y las ventajas para dejarlos, más numerosas. Para Porcel, las acusaciones contra los coches eran infundadas pero sus beneficios, sin embargo, eran patentes. En primer lugar, el coche era un excelente medio para separar las calidades sociales, especialmente para la mujer, cuya honestidad nada tenía que ver con su

\footnotetext{
En que se proponen las conveniencias que tienen y los inconvenientes que causan, aparecida en Sevilla ese año de 1626, BNM R 12944.

34 Algunas licencias de veinticuatros en AGS CC Libro 179 f. 460v, Libro 181 f. 210, Libro 182 f. 260v, Libro 184 ff. 48v, 94v, 358, 377 y Libro 185 ff. 316v, 317, 352 y 477v.

35 AMG Actas Capitulares Libro IX, ff. 101-103.
} 
uso, pues ésta podía ponerse en entredicho en muchas otras circunstancias. La escasez de caballos también era falsa. Si los coches desaparecieran de la corte y algunas grandes ciudades «quedarian sin esplendor sordas y hechas aldeas, cosa indecente para vista de estrangeros». Además, los coches eran "aumento de vida a todo genero de gentes, pues en el verano quitan el sol, y en invierno el agua, frio y lodo, de que el Cavallo no puede escusar». También originaban en las repúblicas «amistades y conmodidades, pues tiniendole un cavallero puede llevar consigo seis y ocho que no los tienen, ni pueden tener cavallos, con que passeandose onestamente se escussan de juegos, y otras cosas peores» ${ }^{36}$.

También participó en la controversia granadina Diego Bello Hurtado con una diatriba contra el uso de los coches que, a los habituales tópicos - libertad de la mujer, pérdida de la caballería y mimetismo social - añadía otros motivos para eliminarlos, como eran los conflictos entre diferentes sectores sociales, los problemas causados por su uso irreverente y sobre todo, un par de cuestiones acuciantes en Granada como en Sevilla, que facilitaban los fraudes a la hacienda real y que provocaban graves problemas higiénicos. A ello se sumaban numerosos conflictos sociales entre diversos grupos de poder, especialmente entre los oidores de la Chancillería y los miembros del concejo. Se quejaba en fin, de que rodaban continuos más de 200 coches y aseguraba que su eliminación, sobre la que la mayoría de los granadinos estaba de acuerdo, había de traer a Granada la paz social de la que parecía carecer ${ }^{37}$. No faltó en el debate el famoso Lisón y Biedma, quien escribió para la ocasión otro memorial cuyos argumentos eran muy similares a los de Bello Hurtado ${ }^{38}$. Estos contribuyeron de forma decisiva a la prohibición dada en diciembre de 1621 , por la que desde entonces nadie podría ir en coche en la ciudad salvo el arzobispo y el presidente de la Chancillería ${ }^{39}$. Como en Sevilla, el caso granadino evidenciaba la ruptura entre los caballeros que tenían coche y los que no, aunque aquí se sumaba otro problema como eran los conflictos protocolarios, cuestión que fue decisiva en la prohibición a decir de algunos ${ }^{40}$. Con todo, a diferencia de lo sucedido en aquella ciudad, los quejosos del coche lograron que la prohibición de usarlo se prolon-

36 Porcel, F.: Pide el bulgo no aya coches, y da para ello las razones siguientes, 1621, AGS, Patronato Real 15/6. Este personaje pertenecía sin duda a la élite granadina, pues entre las licencias concedidas en la ciudad hay dos veinticuatros con este apellido, AGS CC Libro 185 f. 477v y AHN Consejos Leg. 4419/108.

37 El memorial de Bello HuRTADo en AHN Consejos Libro 1429 ff. 302r-304v. La opinión del Consejo de Castilla al respecto en ff. 305r-307v.

38 El memorial de LiSÓN Y BIEDMA en BNM Mss. 18400/ 7. Lisón volvió a ocuparse del tema de forma general en 1622 en sus Discursos y apuntamientos, BNM VE 9/2 f. 12r-v.

39 Para la prohibición, AGS RGS Leg. 1621 XII. Francisco ENRÍQUEZ DE JORQUERA se hizo eco de ella, aunque señalando una fecha equivocada, Anales de Granada, 1646, edición de A. MARÍN OCete, P. GAN JiméneZ y L. Moreno Garzón, Granada, 1987, vol. II, p. 649.

40 Un aviso madrileño detallaba que los coches se quitaron «por las contiendas que había sobre parar», en GonzÁlez PALENCIA, A.: Noticias de Madrid, 1621-1627, Madrid, 1942, p. 16. 
gara durante más de una década sin dejar de funcionar eficazmente, lo que cuestiona el supuesto fracaso de las medidas reformistas relativas a los carruajes ${ }^{41}$.

\subsection{Fiscalizacion y nuevos intentos de jerarquizacion social median- te el coche, $1630-1700$}

\subsubsection{La fiscalización de los coches}

La década de 1630 evidenció que había concluido la institucionalización del coche y con ella su naturalización en la corte hasta el punto que las restricciones a su uso pasaron en la práctica a un segundo plano y se procedió a vender licencias, creando nuevos encochados ${ }^{42}$. Por otro lado, se sucedieron los intentos para fiscalizar los carruajes. Desde los años 1620 se habían oído en las Cortes voces que pedían echar algún tipo de carga en los coches, lo mismo sucedió en el Consejo a fines de esa década y nuevamente en las Cortes a comienzos de la siguiente. La vuelta de los coches en Granada en 1633 se hizo por el sistema de vender las licencias, mientras en 1635 las Cortes vincularon el servicio de los millones con la prohibición del coche mediante una pragmática y la posterior venta de licencias para poder volver a usarlo, aunque el proceso hizo aguas entre ese año y el siguiente. Se prohibió desde entonces ir en coche de mulas sin licencia, como ordenaba la pragmática de 1632, salvo comprando una licencia a 300 ducados, como hicieron muchos, aunque otros fueron en coche de mulas sin licencia y sin labrar las 25 fanegas ${ }^{43}$. Ello, junto a las crecientes necesidades dinerarias de la

41 Que la prohibición funcionó exitosamente lo prueban no sólo las discusiones habidas en las Cortes una década más tarde para que volvieran los coches, sino el escasísimo número de licencias dadas a los pocos titulados que tenían pleitos en la Chancillería, como el duque de Béjar que estaba allí en 1626 y solicitaba licencia para su coche de mulas, concediéndosele por 15 días, como pedía, y luego por otro mes más, mientras se veía su caso, AHN Nobleza Osuna Leg. 383 nº 2. El marqués de Poza que vivía en Cabra y decía que iba a veces a Granada a pleitos pidió licencia «para que las veces que fuere a aquella Çiudad pueda andar en ella en su coche de camino y que anden en el sus parientes criados y amigos», proponiendo la Cámara que se le concediera licencia por tres meses, a lo que accedía el monarca, consulta del 20-VIII-1630, AHN Consejos Leg. 4425/128. El 27 de junio de 1632 se consultaba la petición de licencia del conde de Luque, siendo la Cámara de opinión que fuera por sólo dos meses, AHN Consejos Leg. 4425/127.

42 Muestra de que el ciclo se había agotado no sólo son las ventas de licencias, sino también las propuestas del presidente del Consejo de Castilla, el obispo de Solsona, de volver a la pragmática de 1611, AHN Consejos Leg. 7154/1. Más claramente aun se aprecia en el memorial del conde duque de 1637, Elliott, J. H. y De LA PeÑA, J. F.: Memoriales y cartas del conde duque de Olivares, Madrid, 1981, vols. II, pp. 161-162.

43 Cortes, vols. XXXIX, pp. 488 y 495-496; XLI, pp. 158-159, 161; XLIX, pp. 248, 353 y 483; L, pp. 22, 314-315; LI, pp. 102-103; LIV, p. 464 y LV, pp. 181-182 y 197. Las diferentes opiniones en el Consejo de Castilla en AHN Consejos Leg. 4424/242 y 256, Leg. 4428/96 y Leg. 51438/1. Para la pragmática fallida de 1536 también el anónimo, Noticias de Madrid desde el año de 1636 hasta el de 1638, edición de RODRíGUEZ VILLA, A.: La corte y monarquía de España en los años de 
Corona, condujo a que en años posteriores no faltaran los intentos para fiscalizar los vehículos, es decir, lograr que sus propietarios pagaran alguna cantidad en dinero o en caballos, intentando naturalizar un tipo de impuesto sobre su posesión.

El arbitrio se llevó a efecto en varias ocasiones y se intentó otras, produciendo resultados diversos. En 1651 la cobranza «frutifico muy poco reduciendose casi a solos los Ministros su Producto». En 1658 se volvió a cobrar un impuesto para acopiar dinero para el ejército de Extremadura, con cierto éxito. En 1667, con una situación hacendística aun peor, el tributo sobre los coches estaba de nuevo sobre el tapete, con una clarísima reticencia por parte de los ministros. Esta recaudación fue particularmente difícil y todavía en junio de 1668 coleaban los pagos de los miembros del Consejo de Castilla y tampoco en la calle se había podido completar para esas fechas toda la cobranza ${ }^{44}$.

A pesar de las dificultades de una empresa de este tipo, en la que era evidente que los propios ministros no gustaban de colaborar, no acabaron aquí los intentos de sacar dinero a los que traían coche. En 1675 el donativo propuesto no tuvo éxito por las protestas entre otros, de los caballeros de órdenes militares. La siguiente ocasión que se trató de fiscalizar los coches tuvo lugar en 1684. Entonces, numerosas ciudades se negaron a hacerlo efectivo argumentando la pobreza de sus habitantes u otras causas, como sabemos para las andaluzas especialmente. El concejo sevillano pintaba una ciudad endeudada, sin comercio ni tratos, asegurando que

recayendo esta nueva contribucion en la gentte mas necesittada de la Republica, que son aquellos a quien en este tiempo no pueden sus officios manttener, y los nobles que a fuerza de travajos sustenttan oy los coches por conservar en ellos el lustre de sus obligaciones les es summamentte sensible que sus caudales no puedan alcanzar a executtar lo que su Desseo y obligacion les esta siempre Dictando en servicio de VM.

En Madrid fue el Consejo de Órdenes quien opuso más resistencia y solicitó se eliminara de la cobranza del impuesto a los miembros caballeros, pero el Consejo de Castilla se opuso. Este mismo informaba no obstante al monarca de «las excusas y subterfugios con que responden las personas, a quienes se ha notificado, para eximirse de esta contribucion», hasta el punto de que

sin apremios, embargos, Venta de bienes, hasta llegar a poner guardas o llenar las carceles de pressos, no podra dar considerable frutto esta contribucion, y

\footnotetext{
1636 y 37, Madrid, 1886, p. 10 y las cartas de Quevedo, AsTRANA MARín, L.: Epistolario completo de D. Francisco de Quevedo-Villegas, Madrid, 1946, pp. 282-283 y 374. Para las ventas de licencias AHN Consejos Leg. 13200-130 y 185 y Leg. 13203/13204.

44 Los pormenores en AHN Consejos Leg. 7196/64, Leg. 7135 s.f., Leg. 7168/98 y 121, Leg. 7177/26, Leg. 7178/7, Leg. 7196/64, Libro 1243 ff. 150, 151, 153, 154, Libro 1252 ff. 134, 183, Estado Leg. 692/5 y BNM Mss. 1322 ff. 23r-v.
} 
si, se executasen estas diligencias, fuera el último desconsuelo, y Conturbacion de los Dueños de los coches, que en esta Corte son muchos, y los mas de ellos dignos de alguna atenzion por sus Personas, y Puestos.

No sabemos si la fiscalización de 1684 dio muchos frutos, pero alguno debió ser, pues el impulso de sacar dineros de los coches no cedió y en 1688 se volvió a hablar de una contribución de los coches de rúa y camino, que no pareció prosperar ${ }^{45}$. Con todo, aunque desde el punto de vista del rendimiento fiscal el impuesto sobre los coches nunca fuera una cosa de mucho éxito, especialmente porque nunca fue del agrado del Consejo ni de los contribuyentes, lo interesante de estos intentos es que mostraban las grandes dificultades de someter fiscalmente a los privilegiados por unos enseres que consideraban uno de los mayores símbolos de su status. La fiscalización provocó a la larga además, que el uso del coche fuera asimilado no tanto a un privilegio dado por el rey, la institucionalización, como a un privilegio que adquirían quienes tenían medios para ello.

\subsubsection{Reforma y jerarquización social a través de los coches, 1645-1700}

No fue hasta después del cambio de régimen a mediados de la década de 1640 que se apreció un nuevo impulso restrictivo del uso del coche, incardinado en otro movimiento general de reforma no demasiado conocido. Entonces la política sobre los coches se encaminó a frenar a aquellos que pretendían diferenciarse socialmente gracias a su uso, como los alcaldes de corte ${ }^{46}$, o a aquellos que trataban de alterar la etiqueta y el ceremonial con usos nunca vistos, como

45 AHN Consejos Leg. 51438/1, Leg. 7135 sf., Leg. 7185 sf., Leg. 7196/58 y 64, Libro 1260, ff. 135-137 y 139, Libro 1269 ff. 309 y ss. Ya señalaron algunos de estos intentos de fiscalizar los coches autores como ESPEJO, C.: «Enumeración y atribuciones de algunas juntas de la administración española desde el siglo XVI hasta el año 1800», RBAM, $\mathrm{n}^{\circ} 32,1931$, p. 334 y sobre todo SÁnChez BeLEN, J. A.: La política fiscal en Castilla durante el reinado de Carlos II, Madrid, 1996, pp. 276-277 y Garzon ParejA, M.: La hacienda de Carlos II, Madrid, 1980, pp. 267, 269 y ss. 348 y 506 .

46 Los alcaldes de corte tenía prohibido expresamente el uso de los coches desde 1604, pero con el paso del tiempo habían logrado introducirlo en las rondas. En 1645 se les prohibió taxativamente, AHN Consejos Leg. 7136/1, prohibición que hubo de repetirse en 1649, 1657, 1671, 1673 y 1677, Leg. 7167/87, Leg. 7168/121, 7173/12, Libro 1248 f. 31, Libro 1265 f. 252, Libro 1358, f. 27, Libro 1262, ff. 157-161. A fines de siglo lo tenían todos los alcaldes, como se quejaba un anónimo arbitrista en 1677, asegurando que «se portan con ostentación particularmente en Madrid; y aun en las demás partes, de coche de cuatro mulas, criados, casa grande, visitas y algunas sillas para sus mujeres», cfr. SÁNCHEZ RON, R.I.: Delincuencia y seguridad en el Madrid de Carlos II, Tesis Doctoral, UCM, 1992, pp. 72-73. En 1693 se debatía todavía en el Consejo de Castilla si se había de mandar que los alcaldes andaran siempre a caballo, ordenándose que se ejecutara así, AHN Consejos Leg. 7148 sf. 
hicieran embajadores ${ }^{47}$ y consejeros ${ }^{48} \mathrm{O}$ aquellos que llevaban los coches con seis mulas, lo que era privilegio real ${ }^{49}$, o usaban tiros largos y decoraban los vehículos con nuevas invenciones, como hacían nobles ${ }^{50}$, eclesiásticos y ministros ${ }^{51}$.

47 En 1648 se denunciaba que estos intentaban cada día novedades, entre ellas habían pretendido el año anterior poner sus coches en el lugar que ocupaba el del Presidente del Consejo cuando subía a la consulta. El rey les comunicó mediante el mayordomo de semana que «escusasen estas diferençias». Ese año habían repetido «el mismo atentado» los embajadores de Alemania y Venecia, queriendo que el coche del Presidente les cediera el lugar, con el agravante de que se había vuelto costumbre que los cocheros de los embajadores en lugar de sacar los coches a la plaza de palacio al apearse sus amos, los dejaban en el zaguán impidiendo totalmente salir a los del Consejo a tomar los suyos. El Consejo manifestaba que «porque puede suceder alguna revoluçion que no sea façil de sosegar, se servira VM de repetir las ordenes dadas sobre esto» mandando se dijera a los embajadores que excusaran esta novedad y que no se había de permitir «que el ministro que le representa tan imediatamente aia de çeder a ninguno otro en su casa y corte». El rey respondía que quedaba «mirando y tomando informes de lo que por lo pasado se ba estilado para ordenar lo que convenga», AHN Consejos 7136/1.

48 Los consejeros también fueron amonestados en 1659 por dejar el caballo para ir a besar la mano del rey en coche, práctica que no fue tolerada por el monarca, que ordenó al presidente del Consejo que en la siguiente pascua de Navidad se observara la costumbre de que los Consejos fuesen a caballo. El Consejo respondía que ningún ministro los tenía porque habían servido con ellos al principio de la guerra de Cataluña y no habían comprado otros porque muchos «no tienen con que», de forma que les era forzoso tener coche de mulas para acudir a las obligaciones de su oficio. Además, debido a la saca de caballos para el ejército «son muy pocos los que han quedado en el reino y estos los tienen los señores y caballeros ricos a quien no es licito pedirselos prestados». A más abundamiento, los caballos que quedaban no eran bastantes «para tantos como han menester los consejos de vm y los ministros que suelen acompañarlos, concurriendo todos como concurren a un mismo tiempo a besar la mano de vm». Poco pareció impresionarse el rey con la perorata del Consejo pues contestó que convenía «volver a resucitar una cossa de tanto lucimiento y becha siempre, y assi se executara desde esta Navidad lo $q$ tengo resuelto», AHN Consejo 7136/3.

49 Las primeras noticias significativas de transgresiones de esta regalía son de 1644 y tuvieron por protagonista al duque de Medinaceli, AHN Consejos 7157/8 y 43. Un memorial del duque justificando este y otros usos en RAH Pellicer t. I ff. 71-74. Para las seis mulas del arzobispo de Valencia y los problemas que ocasionó, FERRÁN SALVADOR, V.: «La pragmática de las mulas», Saitabi, 5, 1944, pp. 5-18 y CALlado Estela, E.: «Seis mulas para fray Pedro de Urbina..», art. cit. Una interesante justificación de la regalía en LEYZA Y ERASO, J.: Por el regio fisco sobre la regalia de llevar en la carroça seis mulas, o cavallos, y dos cocheros descubiertos, BPM 18690 (24) s.a. (pero escrito entre 1656 y antes de 1665). En Madrid se prohibió el uso de seis mulas en los coches en 1653, pero tras la muerte de Felipe IV la costumbre se extendió en la corte, cuestionándose de esta forma simbólica el papel de la reina gobernadora y del rey niño. Prohibiciones en este sentido las hubo en 1668, 1670, 1671, 1674 y años posteriores, confundiéndose su prohibición con la de las mulas en los coches de 1678, véase AHN Consejos Libro 1238 f. 119, Libro 1253 ff. 138-140, Libro 1255 ff. 52 y 53, Libro 1256 f. 19, Libro 1260 f. 140, Leg. 7178/49, Leg. 7181/112, AGS Estado Leg. 4128 sf. etc. La trasgresión era tal que la prohibición se acabó incluyendo en la pragmática de 1691.

50 Algunas noticias sobre la ostentación de los carruajes de la aristocracia cortesana en las famosas cartas de los Jesuitas publicadas en Memorial Histórico Español, Madrid, 1861-1865, en adelante, Jesuitas, Cartas, vol. IV, p. 233. vol V, p. 28, vol. VII, pp. 75-76. También da interesantes noticias BARrionuevo, J.: Avisos, BAE, 221, pp. 201, 214, 300, 307, 312 у BAE, 222, pp. 9 y 142.

51 Barrionuevo, Avisos, BAE, 221, pp. 143, 172, 205, 209 y BAE, 222, pp. 186 y 191. También en AHN Consejos Libro 1251 f. 44. Otras denuncias en el ANÓNIMO, Achaques de la 
En esta línea fueron la pragmática de 1657 y otras medidas que se trataron de implementar hasta comienzos de la década de 1670, medidas que no llegaron a fraguar, pues buena parte de ellas fueron dadas en un contexto de debilidad del poder real que facilitó y casi alentó la competencia ${ }^{52}$.

Efectivamente, las diversas reformas ensayadas entre los años 1640-1670 no fueron suficientes para frenar el acceso al coche y los excesos en su decoración y uso y no fue hasta mediados de la década de 1670 que se fraguaron verdaderas pragmáticas restrictivas que incidieron primeramente en la contención del gasto suntuario y que culminaron más tarde en la prohibición expresa del uso del coche a cierto numero de oficios, en concordancia con la preeminencia que tras el confuso periodo 1668-1677, alcanzó la alta nobleza en el gobierno de la Monarquía, en el control del patronato regio y en la vida de la corte ${ }^{53}$.

La competencia suntuaria mediante el coche se había acentuado sin duda con la aparición de las «grands carrosses» francesas, un novedoso tipo de vehículo mejorado técnicamente en relación a los coches anteriores y susceptible de llevar una decoración muy sofisticada ${ }^{54}$. Así, con los ojos puestos en ellas, la pragmática de 1674 prohibió hacer vehículo alguno

bordado de oro, ni de seda, ni afforado en brocado, tela de oro, ni de plata, ni de seda alguna q la tenga, ni cô franjas, ni trêcillas, ni otra guarnicion alguna de pûtas de oro, ni de plata, y solamête se puedâ hazer de terciopelos, o damascos, o de otras qualesquier telas de seda de las fabricadas en estos Reynos, y sus dominios, o en Provincias amigas cô quien tuviere comercio, y solo se puedan guarnecer cô frâjas, y galones de seda, sin q se puedan hazer ni usar por ninguna persona de qualquier grado, y dignidad q sea, ni traer sus coches, carroças, estufas, ni literas, cô labores, ni sobrepuestas, ni labrados los pilares a lo salomonico, y estriados, tallados, ni en otra forma, ni uno ni otro dorado, ni plateado, ni pintado con ningun genero de pinturas.

Monarquía, BNM Mss. 8180, f. 66 y JuderíAs, J.: España en tiempos de Carlos II el hechizado, Madrid, 1912, p. 149.

52 Para la pragmática de 1657 , que prohibía ciertas decoraciones en los coches y que fue repetida en 1659, AHN Consejos Leg. 7255/95. En 1662 y 1667 se discutió de nuevo reducir el gasto en los coches pero sin que se concretara medida alguna, véase, BARRIONUEVo, Avisos, BAE, 222, pp. 269-270 y AHN Consejos Leg. 51438/1. En 1671 y 1672 se volvió a tratar del tema, AHN Consejos Leg. 7137/12.

53 Véase, Álvarez-Ossorio Alvariño, Antonio: «El favor real: liberalidad del príncipe y jerarquía de la república (1665-1700)», en ConTINIsio, Chiara y MOZZARELLI, Cesare: Repubblica e virtù. Pensiero politico e Monarchia Cattolica fra XVI e XVII secolo, Roma, 1995, pp. 393-453.

54 Para la «grand carrosse» de origen francés véase, KREISEL, H.: Prunkwagen und Schlitten, pp. 49 y ss. y WaCKeRNAGEL, Der französische Krönungswagen..., pp. 17 y ss. Véanse los comentarios de J. Herauld sobre su uso en la corte madrileña, en GARCía MERCADAL, J.: Viajes de extranjeros por España y Portugal. Desde los tiempos más remotos hasta comienzos del siglo XX, Valladolid, 1999 (1 edición, 1948), vol. III, p. 573 y Condesa D'AulnoY, Viaje por España en 1679 y 1680, edición de M. Corominas y M.M. Villalta, Barcelona, 1962, t. I, pp. 166-167 y 169. 
Sin embargo, la ley acabó un tanto descafeinada tras el programa de prórrogas que luego tuvo lugar. Quienes llevaban coches a la moda francesa mantuvieron durante tres años sus vehículos, diferenciándose del resto de los cortesanos. Después de algunas quejas y de la opinión del Consejo de que aquella se cumpliera sin excepción, en agosto de 1677 se pregonó otra vez el bando con la disposición ${ }^{55}$. Algo muy parecido sucedió con la pragmática de 1678 que prohibía el uso de mulas en los coches, medida que no llegó a ser eficaz, en parte, por el desinterés del Consejo de Castilla, afectado de lleno por la prohibición que trataba de imponer ${ }^{56}$.

Con todo, los cambios acaecidos en la corte en los años inmediatamente posteriores dieron un nuevo e inesperado protagonismo a las restricciones suntuarias y al acceso al uso del coche que alcanzaron su punto álgido, en paralelo al poder alcanzado por la alta nobleza en la corte y el gobierno de la Monarquía en las últimas dos últimas décadas del siglo. Fue debido a ello que se trató de controlar cualquier atisbo de diferenciación social a través de los carruajes profundizando o ampliando la reforma, proceso que cristalizó en 1684, cuando la pragmática de 1674 fue publicada de nuevo casi en idénticos términos ${ }^{57}$, y que culminó con su repetición y ampliación en 1691. Además de la prohibición de las seis mulas o caballos en los coches, la ley trató de controlar el número de mozos de silla, asunto no tocado en 1674 ni en 1684, a fin de disminuir el excesivo lujo de los señores, prohibiendo que excediesen de cuatro. Aquellos de más habían de perder las «libreas con que fueren aprehendidos» y serían condenados a cuatro años de presidio en África por la primera vez y a seis años de galeras por la segunda. Pero la innovación más importante de la ley fue la prohibición de ir en coche para cierto numero de oficios. De acuerdo al «excesso grande que de algun tiempo a esta parte ha avido en el uso de los coches, y gastos que ocasionan en los caudales de algunas personas que por sus ministerios no deven tenerlos» y siendo justo distinguir a quienes podían usar de ellos «por su decencia», se prohibía traer cualquier tipo de vehículo a

55 Pragmática que su Magestad manda publicar sobre la reformación en el excesso de Traxes, lacayos, y coches, y probibición del consumo de las mercadurías de Francia... y otras cosas, BNM R 23879 (18), ff. 5v-7r y AHN Consejos Leg. 51438/1. Las prórrogas para su cumplimiento en AHN Consejos Libro 1260 ff. 28-29, Libro 1261 f. 65, Libro 1262 ff. 109, 113v-115r y el Vando del Rey para que se cumpla la pragmática del 8 de marzo de 1674 que se había contravenido sobre la reforma de trajes, lacayos y coches, tanto en esta corte como fuera de ella, y para que se ejecuten sentencias a los trangresores, 1677, en BNM R 23879 (18/2).

56 Probibición de usar mulas y machos en coches, estufas, calesas y demás portes de rua, en Novísima Recopilacion, Libro VI, título XIV ley XIII. Para el contexto de esta reforma y las desventajas del uso de las mulas, véase el opúsculo anónimo y sin fecha, pero escrito a la vera del Consejo de Castilla en 1678, Probibición de traer mulas en los coches, BNM 2/ 47622, pp. 1-62. Para las prórrogas y discusiones del Consejo AHN Consejos Leg. 51348/1, Libro 1264 ff. 133, 184, 186r-v y 210.

57 Pragmática que su magestad manda publicar para que se guarde, execute, y observe la que se publicó el año de 1674 sobre la reforma en el Excesso de Trages, Lacayos, y Coches, y otras cosas en esta contenidas, BNM R 23879 (23). Repetía las disposiciones anteriores en los puntos 10, 12, 13, 14, 15, 16 y 18. 
Alguaciles de Corte, Escrivanos de Provincia, y Numero, ni otros ningunos; ni tampoco los han de poder traer los Notarios, Procuradores, Agentes de pleitos, y de negocios, ni los Arrendadores, si no es que por otro titulo honorifico los puedan traer; ni los Mercaderes con tienda abierta, ni los de lonja, Plateros, Maestros de Obras, Receptores desta Villa, Obligados de Abastos, Maestros, ni Oficiales de cualesquier oficios, y maniobras, pena de perdimiento dellos ${ }^{58}$.

Por primera vez en Castilla la ley graduaba quiénes podían hacer uso del coche, como afirmaban sorprendidos los escribanos en el memorial que enviaron al rey pidiendo se les permitiera a ellos ${ }^{59}$. Para hacer cumplir la pragmática, se ordenó hacer un registro de los coches de la corte, so pena de perderlos en cuatro días si no se efectuaba este y se dio un plazo de un año para gastar los vehículos, tras el cual se había de volver a publicar la ley ${ }^{60}$. Desde el comienzo abundaron los problemas por la aplicación de la pragmática que fue conflictiva y duradera ${ }^{61}$ y debió afectar a varias decenas de personajes. Algunos de los excluidos eran grupos muy reducidos, como los alguaciles, o los siete escribanos de provincia y los del número. A algunos de ellos se les negó sin remedio el coche, otros volvieron a subirse a él gracias a sus contactos o a que ya no ejercían los oficios proscritos. El hecho de que fueran relativamente pocos ahondaba en la idea de una justicia implacable y reconocida que no dejaba resquicio alguno al ascenso social ${ }^{62}$.

Entre los que tuvieron éxito en sus intentos de volver a encocharse estuvieron algunos personajes vinculados a la aristocracia o a grandes banqueros, así como grandes comerciantes ${ }^{63}$. Pero otros poseedores de coche no pudieron vol-

58 Pragmática que su magestad manda publicar, para que se guarde y execute y observe la que se publicó el año de 1684 sobre la reformacion en el excesso de Trages, Coches, y otras cosas en esta contenidas, BNM R 23879 (26). Para algunas de las modificaciones introducidas, AHN Consejos Leg. 51438/1. Se prohibían las decoraciones en los coches que en años anteriores, pero se añadía que quedaba prohibido hacer coches pintados «cô ningun genero de pinturas de dibujo, entendiendose por tales todo genero de historiadas, marinas, boscajes, ornatos de flores, mascarones, laços que llaman de cogollos, escudos de Armas, timbres de guerra, prespectivas y otra qualquier pintura que no sea de marmoles fingidos, o jaspeados, de un color todo, eligiendo cada uno el que quisiere». Se permitía a las viudas ir en sillas negras, pero en ningún caso en coches negros.

59 Aunque la ley nunca había regulado este extremo, la praxis seguida en la concesión de las licencias no se había apartado de estos presupuestos desde que comenzara hacía 80 años. Véase infra.

60 AHN Consejos Libro 1279, ff. 272r y ss. Para la repetición de la ley en 1692, ibidem, ff. 478 y ss.

61 A principios de diciembre de 1692 Juan Ibáñez informaba al marqués de Távara que «sobre la oserbazion de los coches de pragmatica ay grande Reboluzion y Presos y Condenaziones Porque no se azia caso», BNM Mss. 10241/84.

62 En su petición para ser excluido de la pragmática, Juan de Retes aseguraba que desde la promulgación de la ley no sacaba el coche porque «no se le hiciese alguna vejacion», AHN Consejos Libro 1277 f. 24. Parecido comentario hicieron casi todos los demás personajes.

63 En febrero de 1693 se declaraba que podía ir en coche don Juan Fedi Arias «que asiste a los negocios de la casa» de don Francisco Esteban Rodríguez, conocido banquero. A instancias de la marquesa de Malagón se concedía licencia en julio de 1693 a don José de la Plaza Otalora, 
ver a usarlo al ser declarados incluidos en la pragmática, como les sucedió a los escribanos, un gremio muy amplio con importantes diferencias de status. Los siete excluidos escribieron un memorial al rey solicitándole les fuera levantada la prohibición. Decían que hallaban «desfavorecida y notada su profession», cuando consideraban que esta era suficiente para poder ir en coche y cuando no eran muchos los que lo poseían entre ellos ${ }^{64}$.

Con todo, algunos de estos personajes volvieron a usar del coche porque tras estos primeros movimientos, el rey resolvió en febrero de 1693 que aquellos incluidos en la pragmática pudieran volver a usar de los carruajes pagando por ello, «procurando sacar desta licencia la maior cantidad que sea posible»65. Sin embargo, la compra de algunas licencias no interrumpió el proceso abierto por la pragmática y hubo nuevas prohibiciones ${ }^{66}$. Puede decirse finalmente que el movimiento reformista iniciado en 1674 y continuado en 1678, 1684 y 1691 parece haber alcanzado al menos un relativo éxito, teniendo en cuenta que parte de sus mismos fundamentos quedaban hechos añicos cuando se daba marcha atrás a la ley o cuando se vendían licencias a quienes hacía apenas unos meses se había desencochado sin remedio. Pero estas aparentes contradicciones, en realidad significaban que era necesario mostrarse permeable o flexible a fin de asegurar cierta movilidad social sin que por ello se perdiera de vista la verdadera razón de ser de toda reforma; la restricción del coche a una pequeña elite cortesana que, si bien es cierto que se había ido ampliando con el paso del tiempo, no parecía haber experimentado un gran crecimiento desde las últimas décadas ${ }^{67}$.

secretario y agente de los negocios de su Casa y estados para que pudiera traer coche «con calidad de que este haya de ser de la dicha señora marquesa de Malagon y que don Joseph no haya de ser agente de mas negocios que los de su casa», AHN Consejos Libro 1278, ff. 74-75. Entre los comerciantes estuvo Luis López Malo, regidor perpetuo de Cuenca y uno de los hombres de negocios de mayor comercio de la corte, que fue declarado fuera de la pragmática, Libro 1276 f. 192.

64 BNM VE 191/83, ff. 5v-6r.

65 AHN Consejos Leg. 51438/1.

66 Véanse los casos de doña Ana Díaz, viuda de la corte y de Juan Pérez Martínez, guantero de cámara del rey, a quienes se les denegó el uso del coche en 1695, AHN Consejos Libro 1280, ff. 56-64v.

67 Según la contabilización realizada en 1684, había unos 900 poseedores de coche en Madrid. Aunque sólo se puede identificar la situación socioprofesional del $60 \%$ de los personajes que aparecen en el listado, de ellos se deduce lo siguiente: había algo más de 170 titulados, que ascendían al $20 \%$ del total de madrileños con coche. Les seguían consejeros, secretarios y abogados de los Consejos, con aproximadamente el $14 \%$ del total. Los eclesiásticos eran el 4,8 \%, los caballeros de Órdenes militares alcanzaban el 4,5\%, los regidores eran el 2\%, los abogados eran menos del $1 \%$, mientras que mercaderes y asentistas, arrendadores y hombres de negocios en conjunto, no llegaban al $2 \%$ del total. Estas cifras, aunque parciales, muestran un tendencia clara; el número de encochados en la corte no había aumentado desde el final de la institucionalización y estos seguían perteneciendo al estamento privilegiado, es decir, a los cortesanos más conspicuos, nobles, caballeros, consejeros y ministros. Para la contabilización, AHN Consejos Libro 1269 ff. 86127. En cuanto a la cifra de 900 poseedores de coche, esta coincide con la contabilización de 1637 que traen las Noticias de Madrid desde el año de 1636 hasta el de 1638, p. 135. 